\title{
UTILIZAÇÃO DA PRODUTIVIDADE DE GRÃOS NA SELEÇÃO PARA RESISTÊNCIA AO Colletotrichum lindemuthianum NO FEIJOEIRO
}

\author{
ÂNGELA DE FÁTIMA BARBOSA ABREU ${ }^{1}$ \\ MAGNO ANTONIO PATTO RAMALHO ${ }^{2}$ \\ FLÁVIA MARIA AVELAR GONÇALVES ${ }^{3}$ \\ HÉLIA ALVES DE MENDONÇA ${ }^{4}$
}

\begin{abstract}
RESUMO - O trabalho foi realizado com o objetivo de verificar se as famílias de feijão (Phaseolus vulgaris L.) com maior produtividade de grãos são as que possuem maior resistência ao Colletotrichum lindemuthianum e, assim, poder utilizar a produtividade de grãos como critério auxiliar na seleção de linhagens mais resistentes. Para isso, foram realizados cruzamentos entre as linhagens AN 730340, AN 910522, AN 910523 e AN 910546, resistentes ao patógeno, com a cultivar Carioca, que é suscetível. A partir da geração $F_{2}$, as populações foram avançadas em dois locais no sul de Minas Gerais, Lavras e Lambari, sen-
\end{abstract}

do selecionadas 100 plantas resistentes (sem sintomas) e 100 suscetíveis (com alta severidade da doença), formando, assim, duas subpopulações por cruzamento em cada local. Essas populações foram conduzidas em "bulk" até a geração $\mathrm{F}_{5}$. Cinqüenta plantas $\mathrm{F}_{5}$ deram origem às famílias $\mathrm{F}_{5: 6} \mathrm{e}$, posteriormente, 21 famílias $\mathrm{F}_{5: 7}$, que foram avaliadas com relação à produtividade de grãos e severidade do patógeno nos dois locais. Constatou-se que, especialmente sob alta severidade da doença, a produtividade de grãos foi um ótimo critério seletivo para identificação de famílias resistentes.

TERMOS PARA INDEXAÇÃO: Antracnose, resistência a doenças, melhoramento.

\section{USE OF GRAIN YIELD TO SELECT FOR RESISTANCE TO Colletotrichum lindemuthianum IN COMMON-BEAN}

\begin{abstract}
This study aimed to investigate whether high yielding common bean (Phaseolus vulgaris L.) families are the ones that show high resistance to Colletotrichum lindemuthianum. If this hypothesis is confirmed, grain yield can be used as criteria for selection of resistant lines to the pathogen. Crosses between the resistant AN 730340, AN 910522, AN 910523 and AN 910546 inbred lines and the susceptible Carioca cultivar were made. From the $\mathrm{F}_{2}$ generation onwards, the segregant populations were taken to Lavras and Lambari in Southern Minas
\end{abstract}

Gerais. A total of 100 resistant plants (without symptoms) and 100 susceptible plants (severe disease incidence) were selected from each populations to form two sub-populations per cross in each location. These sub-populations were conducted in bulk to the $\mathrm{F}_{5}$ generation. Fifty $\mathrm{F}_{5}$ plants were selected to form $50 \mathrm{~F}_{5: 6}$ families and then $21 \mathrm{~F}_{5: 7}$ families, which were assessed for grain yield and pathogen resistance in the two locations. It was found, especially under high disease pressure, that grain yield was an excellent selection criteria to identify resistant families.

INDEX TERMS: Anthracnose, disease resistance, breeding.

1. Engenheiro Agrônomo, Dra. em Genética e Melhoramento de Plantas, Embrapa - Arroz e Feijão.

2. Engenheiro Agrônomo, Dr. em Genética e Melhoramento de Plantas, UNIVERSIDADE FEDERAL DE LAVRAS/ UFLA - Caixa Postal 37 - 37200-000 - Lavras, MG.

3. Engenheiro Agrônomo, Dra. em Genética e Melhoramento de Plantas, Universidade Federal de Viçosa.

4. Engenheiro Agrônomo, Dra. em Genética e Melhoramento de Plantas, Embrapa - Acre. 


\section{INTRODUÇÃO}

Entre as causas de redução da produtividade de uma cultura, a ocorrência de doenças é uma das principais. No caso específico do feijoeiro, a antracnose, causada pelo fungo Colletotrichum lindemuthianum, pode causar perdas de até $100 \%$ da produção se as condições ambientais forem favoráveis ao seu desenvolvimento (Sartorato, 1988; Singh et al., 1991; Trutmann \& Graf, 1993). Por esse motivo, essa doença tem merecido atenção especial nos programas de melhoramento dessa cultura (Abreu et al., 1990a, 1990b; Gonçalves et al., 1996; Abreu et al., 1997), uma vez que a utilização de cultivares resistentes é a alternativa mais eficiente e econômica de controle desse patógeno.

Com base no primeiro relato de resistência ao $C$. lindemuthianum (Bulkholder, 1918), posteriormente inúmeros outros mostraram a existência de várias fontes de resistência (Schreiber, 1932; Young \& Kelly, 1996; Alzate-Marín, 1996). Contudo, são freqüentes as informações sobre a ocorrência de novas raças do patógeno vencendo os alelos de resistência existentes (Rava et al., 1994). Isso faz com que os trabalhos dos melhoristas visando à resistência a esse patógeno seja rotina nos programas de melhoramento.

Na condução de um programa de melhoramento visando à resistência a doenças em condições de campo, a etapa de avaliação é crucial. Isso porque ela depende de uma distribuição uniforme do patógeno e, sobretudo, dos critérios utilizados pelo avaliador. Considerando que a correlação entre a produtividade de grãos e as notas dos sintomas de antracnose é negativa e alta (Ramalho et al., 1993a), é esperado que as famílias mais produtivas sejam também as mais resistentes ao patógeno prevalecente na região. Como na literatura não foi encontrada nenhuma referência a esse respeito, foi realizado o presente trabalho com o objetivo de utilizar a avaliação da produtividade de grãos como critério seletivo auxiliar na identificação de famílias resistentes ao fungo $C$. lindemuthianum

\section{MATERIAL E MÉTODOS}

Foram realizados cruzamentos entre as linhagens AN 730340, AN 910522, AN 910523 e AN 910546, resistentes ao $C$. lindemuthianum, com a cultivar Carioca, que é suscetível ao patógeno. As linhagens AN 730340, AN 910522, AN 910523 e AN 910546, provenientes da Embrapa - Arroz e Feijão, são oriundas de cruzamentos com a linhagem Tu, portadora do alelo Co-5, que confere resistência a várias raças do patógeno. Também apre- sentam grãos tipo carioca, só que de tamanho inferior às exigências do mercado.

Os cruzamentos e a condução da geração $F_{1}$ foram realizados em telado do Departamento de Biologia da Universidade Federal de Lavras (UFLA). Posteriormente, aproximadamente 500 sementes $\mathrm{F}_{2}$ de cada população foram semeadas no campo, em Lavras e Lambari, região sul do Estado de Minas Gerais. Em Lavras, após a germinação, quando as plantas apresentavam a primeira folha trifoliolada, foi feita inoculação com a raça 89. Já em Lambari, como a doença ocorreu naturalmente, não foi feita inoculação. $\mathrm{Na}$ colheita, foram coletadas separadamente de cada população em cada local 100 plantas sem sintomas da doença (consideradas resistentes) e 100 com sintomas (consideradas suscetíveis), que foram conduzidas em "bulk" até a geração $\mathrm{F}_{5}$.

$\mathrm{Na}$ geração $\mathrm{F}_{5}$, baseado no tipo de grão carioca de acordo com as exigências do mercado, selecionaramse 50 famílias de cada população que foram avaliadas na geração $\mathrm{F}_{5: 6}$ em experimentos, nos dois locais. Os experimentos foram conduzidos nas águas de 1997/98 no delineamento látice $20 \times 20$, com duas repetições. As parcelas foram constituídas de uma linha de $2 \mathrm{~m}$, espaçadas de $0,5 \mathrm{~m}$. Por ocasião do enchimento de grãos, foi avaliada a severidade de antracnose, utilizando a escala de notas de 1 a 9 (Rava et al., 1993), em que 1 indica ausência de sintomas e 9, plantas totalmente infectadas. Também foi determinada a produtividade de grãos, em $\mathrm{kg} / \mathrm{ha}$.

Com base nessa avaliação, das populações consideradas suscetíveis, selecionaram-se as 21 famílias com maior nota de antracnose, e das populações consideradas resistentes, as 21 famílias com menor nota. Essas famílias foram novamente avaliadas na geração $F_{5: 7}$ em Lavras e Lambari na "seca" de 1998. Como testemunhas, foram utilizadas as cultivares Carioca (suscetível) e AN 730340 (resistente). O delineamento experimental foi látice 13 x 13 com duas repetições. As parcelas foram constituídas de duas linhas de $2 \mathrm{~m}$, espaçadas de $0,5 \mathrm{~m}$. Também foram avaliadas a produtividade de grãos em $\mathrm{kg} / \mathrm{ha}$ e a incidência de antracnose usando a mesma escala descrita anteriormente.

Os dados da produtividade de grãos e das notas de severidade de antracnose foram submetidos à análise de variância por local e época de semeadura. Também foi estimada a correlação entre a nota de antracnose e a produtividade de grãos e estimados parâmetros genéticos seguindo metodologia apresentada por Ramalho et al. (1993b). 


\section{RESULTADOS E DISCUSSÃO}

Inicialmente deve ser comentado que, com a seleção efetuada para tipo de grão na geração $\mathrm{F}_{5}$, todas as famílias apresentaram grãos tipo carioca dentro do padrão exigido pelo mercado. Constatou-se que ocorreu diferença significativa entre as famílias $\mathrm{F}_{5: 6}$ tanto para produtividade de grãos, quanto para resistência à antracnose, nos dois locais (Tabela 1). Em Lavras, a produtividade média das famílias foi de $1658 \mathrm{~kg} / \mathrm{ha}$, ao passo que em Lambari foi de $1329 \mathrm{~kg} / \mathrm{ha}$. Já com relação à severidade de antracnose ocorreu o inverso, ou seja, foi maior em Lambari que em Lavras, e essa pode ser uma das causas da menor produtividade de grãos nesse local. A cultivar Carioca apresenta alto potencial produtivo na ausência de patógenos (Abreu et al., 1998; Ramalho et al., 1998; Abreu et al., 2001), fato que também foi observado nesse trabalho em Lavras, onde foi menor a severidade da doença. Sua produtividade foi alta e superior à da linhagem AN 730340. Contudo, em Lambari, onde a severidade da doença na 'Carioca' foi maior, sua produtividade foi $23 \%$ inferior à da referida linhagem. A ampla variação observada tanto para a produtividade de grãos quanto para a severidade de antracnose pode ser comprovada pelas estimativas de variância genética e da herdabilidade (Tabela 1), que podem ser consideradas relativamente altas quando comparadas com as obtidas em outros trabalhos com a cultura do feijão (Gonçalves et al., 1996; Nunes et al., 1999; Rosal et al., 2000), o que possibilita antever o sucesso com a seleção para ambas as características.

$\mathrm{O}$ fato de terem sido verificados sintomas de antracnose nas famílias oriundas da população de plantas consideradas resistentes (Tabela 2) pode ser atribuído a alguns fatores. $\mathrm{O}$ primeiro deles é que algumas plantas consideradas resistentes na seleção efetuada na geração $\mathrm{F}_{2}$ podem não ter apresentado sintomas devido a algum escape. Uma outra suposição é que a(s) raça(s) ocorrida(s) por ocasião da avaliação das famílias na geração $\mathrm{F}_{5: 6}$ pode $(\mathrm{m})$ não ser $\mathrm{a}(\mathrm{s})$ mesma(s) devido à variabilidade que pode ser apresentada pelo patógeno (Abreu et al., 1993; Rava et al., 1994). Contudo, isso é pouco provável, pois das 25 raças levantadas por Rava et al. (1994) no Brasil, apenas a 585 vence o alelo Co-5, e essa só foi encontrada em um isolado no Estado do Espírito Santo. Finalmente, como a seleção foi efetuada na geração $F_{2}$, se a resistência nas linhagens utilizadas é devida ao alelo dominante $\mathrm{Co}-5$, as plantas selecionadas podiam ser heterozigotas, o que levou ao aparecimento de plantas suscetíveis nas gerações futuras. Mesmo assim, pode-se observar que as famílias consideradas resistentes quase sempre foram mais produtivas que as suscetíveis (Tabela 2). Além disso, apesar de as correlações entre a produtividade e a incidência de doenças terem sido geralmente baixas, na maioria dos casos foram negativas e significativas, confirmando que a antracnose é uma das causas de redução da produtividade do feijão.

TABELA 1 - Resumo da análise de variância e estimativas da variância genética $\left(\sigma_{\mathrm{G}}^{2}\right)$ e herdabilidade $\left(\mathrm{h}^{2}\right)$ da produtividade de grãos (Kg/ha) e severidade de antracnose (notas de 1 a 9) em 400 famílias de feijão avaliadas na geração $F_{5: 6}$, em Lavras e Lambari nas “águas” 1997/98.

\begin{tabular}{|c|c|c|c|c|c|}
\hline \multirow{3}{*}{ FV } & \multirow{3}{*}{ GL } & \multicolumn{4}{|c|}{ QM } \\
\hline & & \multicolumn{2}{|c|}{ Lavras } & \multicolumn{2}{|c|}{ Lambari } \\
\hline & & Produtividade & Antracnose & Produtividade & Antracnose \\
\hline Famílias & 399 & $408817,4 * *$ & $2,286 * *$ & $263977,3^{* *}$ & $9,623 * *$ \\
\hline Erro efetivo & 361 & 174750,0 & 0,746 & 91422,2 & 1,195 \\
\hline Média geral & & 1658 & 3,0 & 1329 & 3,9 \\
\hline Média Carioca & & 2078 & 4,5 & 925 & 7,1 \\
\hline Média AN 730340 & & 1270 & 1,0 & 1201 & 4,4 \\
\hline Variação & & $575-2942$ & $1,0-7,5$ & $435-5505$ & $1,0-8,5$ \\
\hline $\mathrm{CV}(\%)$ & & 25,20 & 28,80 & 22,70 & 27,90 \\
\hline$\sigma_{G}^{2}$ & & 117033,70 & 0,77 & 86277,55 & 4,21 \\
\hline$h^{2}$ & & 57,25 & 67,37 & 65,37 & 87,58 \\
\hline
\end{tabular}

** Significativo pelo teste $\mathbf{F}$ ao nível de $1 \%$ de probabilidade. 
Constataram-se também plantas resistentes nas famílias nas quais eram esperadas só plantas suscetíveis (Tabela 2). A explicação mais plausível é que quando da avaliação das famílias, possa ter ocorrido má distribuição do patógeno, já que a infestação foi natural, fazendo com que algumas não manifestassem sintomas na magnitude para serem consideradas suscetíveis.

Quando da avaliação das 21 famílias $\mathrm{F}_{5: 7}$ mais resistentes e mais suscetíveis, não foi constatada diferença significativa entre as famílias de nenhuma população quanto à produtividade de grãos no experimento conduzido em Lavras, onde não houve ocorrência do patógeno (Tabela 3). A produtividade média obtida nesse local pode ser considerada alta, $2857 \mathrm{Kg} / \mathrm{ha}$. Mesmo entre as famílias consideradas suscetíveis pelas avaliações nas safras passadas, a produtividade foi alta, sendo a menor de $2665 \mathrm{Kg} / \mathrm{ha}$ (Tabela 4). Inclusive a cultivar Carioca, utilizada como padrão de suscetibilidade, apresentou produtividade de $3644 \mathrm{Kg} / \mathrm{ha}$. Nesse caso, a nãoocorrência de antracnose permitiu que todos os materiais expressassem seu potencial produtivo.
Confirmando as observações anteriores, quando a incidência da doença foi alta, como ocorreu em Lambari, constatou-se diferença significativa entre as famílias de todos os cruzamentos, tanto para produtividade de grãos quanto para antracnose (Tabela 4). A produtividade variou de 459 a $2509 \mathrm{Kg} / \mathrm{ha}$ e a nota de antracnose de 1,0 a 8,5, ou seja, foram observados materiais resistentes até altamente suscetíveis. Em todos os cruzamentos, a produtividade das famílias suscetíveis foi inferior à das famílias resistentes. $\mathrm{O}$ efeito da antracnose na produtividade pôde ser observado principalmente pelas correlações significativas e negativas entre as duas características. Resultados semelhantes foram obtidos por Singh et al. (1991), ao avaliarem a eficiência da seleção para produtividade de grãos e resistência à antracnose e mancha-angular. Esses autores verificaram que, sob alta ocorrência natural do patógeno, os genótipos suscetíveis foram eliminados ainda na fase de plântula e que a seleção para resistência permitiu a manutenção das plantas mais produtivas nas gerações avançadas.

TABELA 2 - Produtividade média de grãos (Kg/ha), nota média para a reação à antracnose (A) e estimativa da correlação (r) entre as duas características em famílias de feijoeiro resistentes e suscetíveis avaliadas em Lavras e Lambari nas "águas" de 1997/98.

\begin{tabular}{|c|c|c|c|c|c|c|c|}
\hline \multirow{2}{*}{ Cruzamento } & \multirow{2}{*}{$\begin{array}{c}\text { Reação à } \\
\text { antracnose }\end{array}$} & \multicolumn{3}{|c|}{ Lavras } & \multicolumn{3}{|c|}{ Lambari } \\
\hline & & Prod. & $\mathbf{A}^{\underline{1} /}$ & $\mathbf{r} \stackrel{2 l}{ }$ & Prod. & $\mathbf{A}$ & $\mathbf{r} \stackrel{2 l}{ }$ \\
\hline AN 730340 x Carioca & Resistente & 1541 & 2,1 & $-0,18$ & 1352 & 3,2 & $-0,48^{* *}$ \\
\hline AN 730340 x Carioca & Suscetível & 1514 & 3,0 & & 1386 & 3,7 & \\
\hline AN 910522 x Carioca & Resistente & 1842 & 3,0 & $-0,36^{* *}$ & 1310 & 4,4 & $-0,23 * *$ \\
\hline AN 910522 x Carioca & Suscetível & 1498 & 4,1 & & 1247 & 5,1 & \\
\hline AN 910523 x Carioca & Resistente & 1826 & 3,0 & $-0,26^{* *}$ & 1283 & 4,8 & $-0,46 * *$ \\
\hline AN 910523 x Carioca & Suscetível & 1626 & 3,9 & & 1403 & 3,5 & \\
\hline AN 910546 x Carioca & Resistente & 1718 & 2,9 & $-0,15$ & 1434 & 2,2 & $-0,47 * *$ \\
\hline AN 910546 x Carioca & Suscetível & 1699 & 3,9 & & 1194 & 4,3 & \\
\hline
\end{tabular}

1/Antracnose: notas de 1,0 a 9,0, em que 1,0 indica ausência de sintomas e 9,0, plantas totalmente infectadas.

${ }^{2 /}$ A correlação foi estimada considerando as famílias resistentes e suscetíveis em conjunto. 
TABELA 3 - Resumo das análises de variância da produtividade de grãos ( $\mathrm{Kg} / \mathrm{ha})$ e da incidência de antracnose nas famílias $\mathrm{F}_{5: 7}$ do cruzamento entre as linhagens AN 730340, AN 910522, AN 910523 e AN 910546 com a cultivar Carioca - Lavras e Lambari - "seca"/1998.

\begin{tabular}{|c|c|c|c|c|}
\hline \multirow{3}{*}{ FV } & \multirow{3}{*}{ GL } & \multicolumn{3}{|c|}{ QM } \\
\hline & & \multirow{2}{*}{$\begin{array}{c}\text { Lavras } \\
\text { Produção }\end{array}$} & \multicolumn{2}{|c|}{ Lambari } \\
\hline & & & Produção & Antracnose \\
\hline Famílias & 168 & 33733,125 & 322809,625 & $0,553^{* *}$ \\
\hline AN $730340 \times$ Carioca & 41 & 405287,675 & 335671,525 & $0,501 * *$ \\
\hline AN 910522 x Carioca & 41 & 289714,525 & $250646,000^{* *}$ & $0,524 * *$ \\
\hline AN 910523 x Carioca & 41 & 374525,550 & $409501,350^{* *}$ & $0,588^{* *}$ \\
\hline AN 910546 x Carioca & 40 & 253560,400 & $262903,175^{* *}$ & $0,600^{* *}$ \\
\hline Testemunhas (T) & 1 & 173884,825 & $597034,375^{*}$ & 0,564 \\
\hline Entre cruzamentos $(\mathrm{C})$ & 3 & 377538,675 & $636330,175^{* *}$ & $0,686^{* *}$ \\
\hline $\mathrm{T}$ vs $\mathrm{C}$ & 1 & $1355597,750^{*}$ & 381316,35 & 0,102 \\
\hline Erro efetivo & 144 & 303696,250 & 149713,550 & 0,194 \\
\hline Média & & 2856,7 & 1695,1 & 2,968 \\
\hline Variação & & $1324,8-3785,1$ & $459,0-2508,7$ & $1,0-8,5$ \\
\hline CV (\%) & & 19,3 & 22,8 & 27,7 \\
\hline
\end{tabular}

* e ** Significativo pelo teste $\mathbf{F}$ aos níveis de $5 \%$ e $1 \%$ de probabilidade.

TABELA 4 - Produtividade média de grãos (Kg/ha), nota média para a reação à antracnose e correlação (r) entre as duas características em famílias de feijoeiro resistentes e suscetíveis avaliadas em Lavras e Lambari na "seca" de 1998.

\begin{tabular}{|c|c|c|c|c|c|}
\hline \multirow{2}{*}{ Cruzamento } & \multirow{2}{*}{$\begin{array}{c}\text { Reação à } \\
\text { Antracnose }\end{array}$} & \multirow{2}{*}{$\begin{array}{c}\operatorname{Lavras}^{\underline{1}} \\
\text { Prod. }\end{array}$} & \multicolumn{3}{|c|}{ Lambari } \\
\hline & & & Prod. & Antracnose $\underline{2 l}$ & $\mathbf{r} \underline{3 /}$ \\
\hline AN 730340 x Carioca & Resistente & 2906 & 1661 & $2,5(1,0-7,0)$ & $-0,48^{* *}$ \\
\hline AN 730340 x Carioca & Suscetível & 2731 & 1595 & $3,3(1,0-8,0)$ & \\
\hline AN 910522 x Carioca & Resistente & 2983 & 1852 & $2,0(1,0-4,5)$ & $-0,59^{* *}$ \\
\hline AN 910522 x Carioca & Suscetível & 2837 & 1474 & $4,8(1,5-8,0)$ & \\
\hline AN 910523 x Carioca & Resistente & 2944 & 1920 & $1,3(1,0-2,0)$ & $-0,63^{* * *}$ \\
\hline AN 910523 x Carioca & Suscetível & 2665 & 1589 & $4,6(1,0-8,0)$ & \\
\hline AN 910546 x Carioca & Resistente & 2899 & 1776 & $1,4(1,0-3,0)$ & $-0,70^{* * *}$ \\
\hline AN 910546 x Carioca & Suscetível & 2826 & 1644 & $4,0(1,0-8,5)$ & \\
\hline Carioca & Suscetível & 3644 & 1700 & 4,5 & - \\
\hline AN 730340 & Resistente & 3227 & 2675 & 1,0 & - \\
\hline
\end{tabular}

${ }^{1 /}$ Em Lavras não houve incidência de antracnose.

2/Antracnose: notas de 1,0 a 9,0, em que 1,0 indica ausência de sintomas e 9,0, plantas totalmente infectadas. Entre parênteses é apresentada a variação das notas.

${ }^{3 /}$ A correlação foi estimada considerando as famílias resistentes e suscetíveis em conjunto. 
Assim, pelos resultados obtidos, pode-se concluir que em condições de alta incidência de antracnose só se destacarão em produtividade de grãos aquelas famílias que apresentarem um bom nível de resistência ao patógeno, o que reforça a importância econômica dos danos causados pelo $C$. lindemuthianum no feijoeiro. Considerando que em praticamente todos os programas de melhoramento a produtividade é sempre o caráter que recebe maior atenção, os resultados obtidos neste trabalho evidenciam que mesmo não sendo efetuada a seleção para resistência ao $C$. lindemuthianum, indiretamente isso é efetuado, sem custo adicional, pela identificação das famílias mais produtivas. Dessa forma, a produtividade de grãos pode ser utilizada isoladamente ou em conjunto com a nota de doença para realizar com maior eficiência a eliminação das famílias e/ou linhagens suscetíveis ao patógeno.

Deve ser ressaltado, contudo, que se o objetivo do programa for selecionar linhagens totalmente resistentes, somente a produtividade de grãos pode não ser um bom indicativo da resistência, pois as cultivares que apresentam poucos sintomas podem não ter a produtividade afetada. $\mathrm{O}$ critério seria interessante apenas para descartar os materiais altamente suscetíveis, pois, nesse caso, como ocorre com a cultivar Carioca, quando o ataque da doença é intenso, a produtividade é drasticamente reduzida.

\section{AGRADECIMENTOS}

À Fundação de Amparo à Pesquisa do Estado de Minas Gerais (FAPEMIG), pelo apoio financeiro.

\section{REFERÊNCIAS BIBLIOGRÁFICAS}

ABREU, A. de F. B.; RAMALHO, M. A. P.; ANDRADE, M. J. B. de; PEREIRA FILHO, I. A. Estabilidade de linhagens de feijão em algumas localidades do estado de Minas Gerais no período de 1994 a 1995. Ciência e Agrotecnologia, Lavras, v. 22, n. 3, p. 308312, 1998.

ABREU, A. de F. B.; RAMALHO, M. A. P.; MENDONÇA, H. A. de; SANTOS, J. B. dos. Obtenção de linhagens de feijoeiro com grãos do tipo carioca e resistente à antracnose. In: EMPRESA DE PESQUISA AGROPECUÁRIA DE MINAS GERAIS. Projeto feijão: relatório 1993/95. Viçosa, 1997. p. 97-100.

ABREU, A. de F. B.; RAMALHO, M. A. P.; MENU, H. M. R. Identificação de raças de Colletotrichum lin- demuthianum do Sul e Alto Paranaíba de Minas Gerais. In: REUNIÃO NACIONAL DE PESQUISA DE FEIJÃO, 4., 1993, Londrina. Resumos... Londrina: IAPAR, 1993. p. 45.

ABREU, A. de F. B.; RAMALHO, M. A. P.; SANTOS, J. B. dos. Desempenho de linhagens de feijão carioca na década de noventa em Minas Gerais. In: CONGRESSO BRASILEIRO DE MELHORAMENTO DE PLANTAS, 1., 2001, Goiânia. Anais... Goiânia: Embrapa, 2001.

ABREU, A. de F. B.; RAMALHO, M. A. P.; SANTOS, J. B. dos. Seleção de famílias de feijoeiro (Phaseolus vulgaris L.) de porte ereto e resistentes à antracnose, provenientes do cruzamento das cultivares Carioca $80 \mathrm{x}$ Rio Tibagi. Ciência e Prática, Lavras, v. 14, n. 1, p. 83-90, 1990a.

ABREU, A. de F. B.; RAMALHO, M. A. P.; SOUZA, E. A. de; SANTOS, J. B. dos. Seleção de cultivares de feijão (Phaseolus vulgaris L.) precoce com grãos tipo carioca e resistentes a antracnose. Ciência e Prática, Lavras, v. 14, n. 1, p. 72-82, 1990 b.

ALZATE-MARÍN, A. L. Resistência à antracnose do feijoeiro (Phaseolus vulgaris L.): diversidade genética de raças de Colletotrichum lindemuthianum, herança da resistência e identificação de marcadores moleculares. 1996. 65 p. Tese (Doutorado em Genética e Melhoramento de Plantas) - Universidade Federal de Viçosa, Viçosa.

BULKHOLDER, W. H. The production of na anthracnose resistant White Marrow bean. Phytopathology, Saint Paul, v. 8, p. 353-359, 1918.

GONÇALVES, P. R.; RAMALHO, M. A. P.; ABREU, A. de F. B. Obtenção de linhagens de feijoeiro comum (Phaseolus vulgaris L.) com grãos tipo carioca e resistente à antracnose e à mancha angular. Ciência e Agrotecnologia, Lavras, v. 20, n. 2, p. 183-190, 1996.

NUNES, G. H. de S.; SANTOS, J. B. dos; RAMALHO, M. A. P.; ABREU, A. de F. B. Seleção de famílias de feijão adaptadas às condições de inverno do Sul de Minas Gerais. Pesquisa Agropecuária Brasileira, Brasília, v. 34, n. 11, p. 2051-2058, 1999.

RAMALHO, M. A. P.; ABREU, A. de F. B.; GONÇALVES, F. M. A. Reliability of common bean lines evaluated en the state of Minas Gerais, Brazil.

Ciênc. agrotec., Lavras. V.27, n.2, p.363-369, mar./abr., 2003 
Annual Report of the Bean Improvement Cooperative, New York, v. 41, p. 194-195, 1998.

RAMALHO, M. A. P.; ABREU, A. de F. B.; MENDONÇA, H. A. de. Melhoramento visando a obtenção de cultivares de feijão resistentes à antracnose. In: REUNIÃO NACIONAL DE PESQUISA DE FEIJÃO, 4., 1993, Londrina. Resumos... Londrina: IAPAR, 1993a. p. 111.

RAMALHO, M. A. P.; SANTOS, J. B. dos; ZIMMERMANN, M. J. de O. Genética quantitativa em plantas autógamas: aplicações ao melhoramento do feijoeiro. Goiânia: UFG, 1993b. 271 p.

RAVA, C. A.; MOLINA, J.; KAUFFMANN, M.; BRIONES, I. Determinación de razas fisiológicas de Colletotrichum lindemuthianum en Nicaragua. Fitopatologia Brasileira, Brasília, v. 18, n. 3, p. 388-391, 1993.

RAVA, C. A.; PURCHIO, A. F.; SARTORATO, A. Caracterização de patótipos de Colletotrichum lindemuthianum que ocorrem em algumas regiões produtoras de feijoeiro comum. Fitopatologia Brasileira, Brasília, v. 19, n. 2, p. 167-172, 1994.

ROSAL, C. J. de S.; RAMALHO, M. A. P.; GONÇALVES, F. M. A.; ABREU, A. de F. B. Seleção precoce para a produtividade de grãos no feijoeiro. Bragantia, Campinas, v. 59, n. 2, p. 189-195, 2000.
SARTORATO, A. Antracnose. In: ZIMMERMANN, M. J. de O.; ROCHA, M.; YAMADA, T. (Orgs.). Cultura do feijoeiro: fatores que afetam a produtividade. Piracicaba: POTAFOS, 1988. p. 457-477.

SCHREIBER, F. Resistenzzchtung bei Phaseolus vulgaris. Phytopathology, Saint Paul, v. 4, p. 415-454, 1932.

SINGH, S. P.; PASTOR-CORRALES, M. A.; MOLINA, A.; URREA, C.; CAJIAO, C. Independent, alternate, and simultaneous selection for resistance to anthracnose and angular leaf spot and effects on seed yield in common bean (Phaseolus vulgaris L.). Plant Breeding, Berlin, v. 106, p. 312-318, 1991.

TRUTMANN, P.; GRAF, W. The impact of pathogens and arthropod pests on common bean production in Rwanda. International Journal of Pest Management, Cambridge, v. 39, p. 328-333, 1993.

YOUNG, R. A.; KELLY, J. D. Characterization of the genetic resistance to Colletotrichum lindemuthianum in common bean differential cultivars. Plant Disease, Saint Paul, v. 80, p. 650-654, 1996. 